https://helda.helsinki.fi

\title{
Fuel consumption analysis of driven trips with respect to route choice
}

\author{
Gilman, Ekaterina
}

IEEE Computer Society

2020

Gilman , E , Tamminen , S , Keskinarkaus , A , Anagnostopoulos , T , Su , X , Pirttikangas , S \& Riekki , J 2020 , Fuel consumption analysis of driven trips with respect to route choice . in 2020 IEEE 36TH INTERNATIONAL CONFERENCE ON DATA ENGINEERING WORKSHOPS (ICDEW 2020). IEEE International Conference on Data Engineering Workshop , IEEE Computer Society , pp. 40-47, IEEE International Conference on Data Engineering , Dallas , United States , 20/04/2020 . https://doi.org/10.1109/ICDEW49219.2020.000-9

http://hdl.handle.net/10138/325496

https://doi.org/10.1109/ICDEW49219.2020.000-9

acceptedVersion

Downloaded from Helda, University of Helsinki institutional repository.

This is an electronic reprint of the original article.

This reprint may differ from the original in pagination and typographic detail.

Please cite the original version. 


\title{
Fuel consumption analysis of driven trips with respect to route choice
}

\author{
Ekaterina Gilman*, Satu Tamminen ${ }^{\ddagger}$, Anja Keskinarkaus ${ }^{\S}$, Theodoros Anagnostopoulos ${ }^{\Uparrow * *}$, \\ Xiang Sull*, Susanna Pirttikangas*, Jukka Riekki* \\ ${ }^{*}$ Center for Ubiquitous Computing, University of Oulu, Finland, firstname.lastname@oulu.fi \\ ‡Biomimetics and Intelligent Systems Group, University of Oulu, Finland, firstname.lastname@oulu.fi \\ $\S$ Center for Machine Vision and Signal Analysis, University of Oulu, Finland,firstname.lastname@oulu.fi \\ IDepartment of Infocommunication Technologies, ITMO University, Saint Petersburg, Russia \\ ** Department of Business Administration, University of West Attica, Athens, Greece, thanag@di.uoa.gr \\ " Department of Computer Science, University of Helsinki, Finland, firstname.lastname@ helsinki.fi
}

\begin{abstract}
Advances in technology equip traffic domain with instruments to gather and analyse data for safe and fuel-efficient traveling. In this article, we elaborate on the effects that taxi drivers' route selection has on fuel efficiency. For this purpose, we fuse real driving behaviour data from taxi cabs, weather, digital map, and traffic situation information to gain understanding of how the routes are selected and what are the effects in terms of fuel-efficiency. Analysis of actually driven trips and their quickest and shortest counterparts is conducted to find out the fuel-efficiency consequences on route selection. The judgments are used for developing a fuel-consumption model, exploring further the route characteristics and external factors affecting fuel consumption.
\end{abstract}

Index Terms-data fusion, fuel-efficiency, route selection, traffic analysis

\section{INTRODUCTION}

Route choice selection is an actively studied research area. Advancements in sensing technologies allow collecting data from real vehicles and their analysis for the possible factors affecting route selection. Examples of such factors are general characteristics, such as time, distance, congestion, signposting and scenery [2], socio-economic characteristics [23], and even personal and cognitive characteristics of drivers like route knowledge [3], capabilities to learn, organise and recall spatial information, sensation seeking capabilities [1], and individual portfolios of strategies of drivers [25].

Route selection affects driving behaviour and, in turn, fuel-efficiency [5], [11], [26]. For instance, traffic lights and pedestrian crossings may require slowing down, idling, and accelerating. Keeping the speed stable improves fuel economy while frequent changes and low speeds reduce it [10].

Taxi GPS traces are valuable sources of data, as nowadays many taxi companies equip their cars with sensing technologies. Taxi GPS traces have been used, for example, to find patterns in origin-destination flows [29], and to suggest night bus routes [7]. Due to great experience of taxi drivers in city driving, it is beneficial to mine their route selection strategies to explore if they are fuel-efficient. Surprisingly, all potentially useful information, like weather, traffic and road condition is not utilised much in related work. To bridge this gap, we fuse driving behaviour, route characteristics, weather and traffic density information to explore whether routes selected by taxi drivers are more fuel efficient than their corresponding shortest and quickest counterparts having the same origin and destination. Methods and lessons learned from this article are general, suggesting their use in other similar studies.

The remainder of the article is organized as follows: Section II introduces the related work. We present our data and data preparation procedure in Section III and present a comprehensive analysis of the driven trips and their shortest and quickest counterparts in Section IV. Section V concludes the paper with summarizing our contributions and discussing the limitations of our study.

\section{RELATED WORK}

Driving behaviour significantly affects fuel consumption [10], [26]. Researchers in both academia and industry have studied instructing drivers in more fuel-efficient driving [14]. Some systems provide online feedback for drivers [15], [27]. Others present deeper post-driving analysis of the trips driven [13]. Many factors affect driving behaviour and route characteristics is one of them, such as traffic lights and pedestrian crossings [5], [10], [26]. However, not only the route itself is important, but the overall situation, including traffic situation on the road and weather [13]. That is why navigator operators encode information about traffic situation in their products. Crowd-sourcing solutions are also suggested. For example, Saremi et al. [24] propose GreenGPS navigation service allowing drivers to find between arbitrary end-points the most fuel-efficient routes customised for their vehicles. Their system aggregates information from vehicles and generalises it to arbitrary roads and cars to suggest the fuel-efficient routes.

Understanding which factors are important for drivers in route selection would allow developing better transportation solutions and infrastructure. Often, alternative routes, minimising some characteristics like time, distance, or number of turns, are constructed and compared with actually driven ones. For instance, Zhu and Levinson [30] fuse GPS and GIS data to analyse the routes taken by the residents up to 13 weeks and reveal that current route choice set generation algorithms do not reveal the majority of paths the individuals took. 
Indeed, different factors can be important for an individual when making driving route decisions [3], [23], [25]. For example, Papinski and Scott [22] identified the following factors important in selecting the route for home-to-work trips based on analysis of 237 trips: gender, household size, work schedule, actual distance to work, distance to central business district, travel time, and exposure to public transit.

Often, research on route selection is based on taxi GPS traces [6], [9]. Yao et al. [28] find taxi drivers' preferences for route choice, like routes with higher driving speed. Route selection heuristic rules are proposed based on a model of the urban space with relationships between urban features and human cognition [19], [20].

Development of tools for route choice analysis is important, as considerable efforts are required to process raw data. Papinski and Scott [21] have developed a GIS-based toolkit for analysing route choices, importing automatically route information and generating over 40 variables describing the route. A similar tool for route analysis has been proposed by $\mathrm{Lu}$ et al. [18]. The authors extracted alternative routes for origin-destination pairs from the actual dataset, hence, only realistic routes were considered for comparison. Moreover, understanding actual situation is important to grasp route choice decision-making. For instance, Jiang et al. [17] suggest a route choice analytical model that uses cumulative prospect theory and evolutionary game theory to analyse drivers' route choice decisions based on the traffic information.

As can be seen, considerable amount of research has been conducted towards both understanding what affects route selection and fuel consumption. Surprisingly, all potentially useful information, such as weather, traffic and road condition is not utilised much in related work. Finally, the fuel consumption for alternative routes is evaluated as well. Our study differs from related work in these aspects.

\section{DATA}

In this study, we fuse weather ${ }^{1}$ traffic situation ${ }^{2}$, route information ${ }^{3}$, and real taxi trips' driving dat ${ }^{4}$ retrieved from the OBDII diagnostics connectors. Table II summarizes the information used in this study. Details of the data sources and corresponding data processing can be found in [13]. Driving data is collected for the period from 9/2012 till 11/2014 from six local taxi cabs. Trips falling outside the local region and trips with insufficient data were removed from the analysis, resulting in 2548 trips considered for analysis.

Each trip was further map-matched [4] and selected driving behaviour characteristics [10] of the trip were calculated (Behavioural characteristics in Table I], check details from [13]. Then, for each trip we generated quickest (least amount of time to travel) and shortest (having minimum distance to travel) routes having the same origin and destination as the original trip. For each route driven and for its shortest and quickest

\footnotetext{
${ }^{1}$ Digitraffic, http://www.infotripla.fi/digitraffic/doku.php?id=start_en

${ }^{2}$ Oulunliikenne, http://www.oulunliikenne.fi/\#/autoilu

${ }^{3}$ Digiroad, a database of Finnish road network

${ }^{4}$ Driveco, http://eco.driveco.fi/www/
}

TABLE I

Processed Route Properties Used for Analysis, [13]

\begin{tabular}{|c|c|}
\hline Characteristics & Properties interpretation \\
\hline $\begin{array}{l}\text { Behavioural } \\
\text { (selected } \\
\text { factors from } \\
{[10] \text { ) }}\end{array}$ & $\begin{array}{l}\% \text { of time with the speed }<2 \mathrm{~km} / \mathrm{h} \\
\% \text { of time with the speed }\{0-15,15-30,30-50,50- \\
70,70-90,90-110,>110\} \mathrm{km} / \mathrm{h} \\
\% \text { of time with the engine speed }\{<1500,1500- \\
2500,2500-3500,>3500\} \\
\text { Speed oscillations (local max and min) per driven } \\
\text { meter } \\
\% \text { of time when multiplication of speed and accel- } \\
\text { eration is } 3-10 \mathrm{~m}^{2} / \mathrm{s}^{3} \\
\% \text { when the acceleration }>2.5 \mathrm{~m} / \mathrm{s}^{2} \\
\text { Relative positive acceleration } \\
\text { Average deceleration }\end{array}$ \\
\hline $\begin{array}{l}\text { Spatial (data } \\
\text { fetched from } \\
\text { Digiroad } 3 \\
\text { digital map) }\end{array}$ & $\begin{array}{l}\text { \% of the trip distance driven on the road with speed } \\
\text { limit }\{20,40,50,60,80,100,120\} \mathrm{km} / \mathrm{h} \\
\text { Number of traffic lights per meter in the route } \\
\text { Number of crossings per meter in the route } \\
\text { Number of pedestrian or bicycle crossings per meter } \\
\text { in the route } \\
\text { Type of the road (physical or traffic-type attributes) } \\
\text { telling \% of the trip driven on }\{\text { motorway, part of a } \\
\text { multiple carriageway which is not a motorway, part } \\
\text { of a single carriageway, roundabout, slip road }\} \\
\% \text { of trip driven on road type }\{\text { road, street, private }\} \\
\text { Functional class of the road (service level of the road } \\
\text { to the traffic) telling } \% \text { of trip driven on }\{\text { regional } \\
\text { main (class I) street, local main street, connecting } \\
\text { road, feeder street/class I private road, class II private } \\
\text { road } \\
\text { Number of }\{\text { left, right }\} \text { turns per meter in the route }\end{array}$ \\
\hline Weather & $\begin{array}{l}\text { Air, surface and dew point temperature } \\
\text { Relative humidity } \\
\text { Surface condition (grip with the surface of the road) } \\
\text { Precipitation intensity and type } \\
\text { Visibility } \\
\text { Friction coefficient } \\
\text { Amount of snow, water and ice on the road }\end{array}$ \\
\hline $\begin{array}{l}\text { Traffic } \\
\text { situation }\end{array}$ & $\begin{array}{l}\text { Ratio of the route driven with }\{\text { bad, constrained, } \\
\text { smooth }\} \text { traffic }\end{array}$ \\
\hline
\end{tabular}

versions, we calculated the spatial map properties (Spatial characteristics in Table I) and assigned weather measurements (Weather characteristics in Table I) [13].

In addition, based on traffic situation information of each route segment, we calculated the ratio of smooth, constrained, and bad traffic situations based on type of the day (working day or weekend) and the time of the trip (morning, day, evening, late evening, and night) for driven routes and corresponding quickest and shortest versions (Traffic situation characteristics in Table I).

To evaluate the similarity of the driven route to generated versions we use overlapping coefficient (OC), which is the ratio of the identical part's length between the route and its generated counterpart to the length of the driven route.

The threshold for labelling two routes to be similar varies. The amounts of routes in this study considered similar to corresponding shortest, quickest, or both counterparts based on different thresholds are presented with Fig 1 c. In our case, quite many trips follow the route close to the corresponding quickest or shortest counterpart. For example, more than third part of trips differs less than $0.1 \%$ from their corresponding 

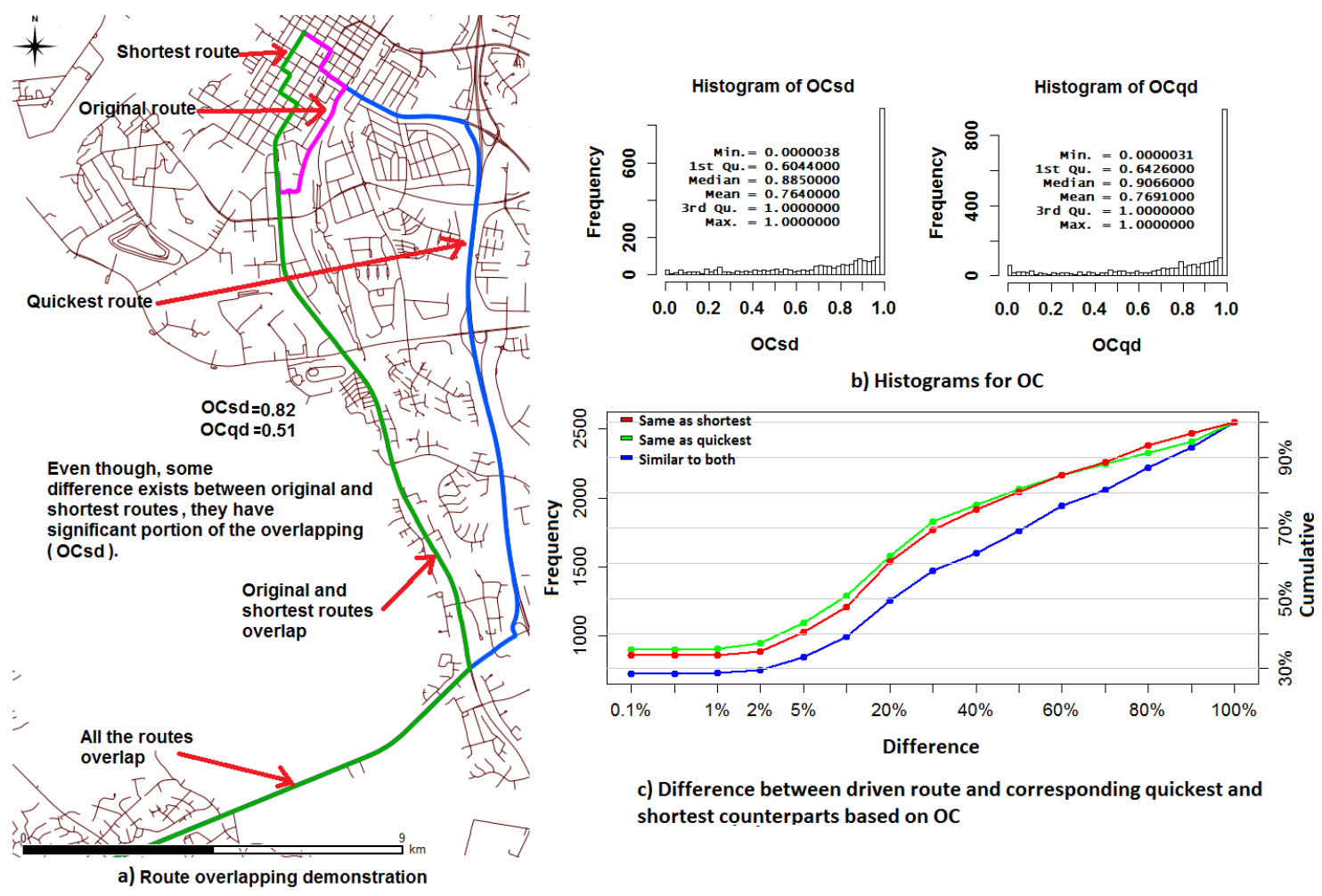

c) Difference between driven route and corresponding quickest and shortest counterparts based on $O C$

Fig. 1. Comparison of the trajectories and statistics for the metrics used.

shortest or quickest counterparts. By relaxing the threshold to $5 \%$ we end up having about $40 \%$ of routes similar to their shortest counterparts and about $43 \%$ similar to their quickest counterparts. Threshold of $10 \%$ allows considering almost half of the routes in the dataset similar to the quickest $(50 \%)$ or shortest (47\%) counterparts. This can be explained by the topology of the road network (plenty of square-like regions) and the nature of the routes taken. Based on this information (Fig/1 and Fig/1k), and based on visual inspection of the routes and their quickest and shortest counterparts, we consider the routes similar to its corresponding quickest or shortest counterpart if they differ less than or equal to $2 \%$ $(\mathrm{OC} \geq 0.98)$, similarly to [30]. Also, we conclude that having $20 \%$ difference in overlap is sufficient to consider the routes as quite different. Larger threshold could hide the real variability between routes close to city centre and smaller threshold would mark insignificant trajectory changes as different and blur the results.

Hence, all the trips for analysis were divided into four groups, as presented in Table III. The first group contains the trips which have the same trajectory as the shortest ones (Shortest). That is, we labelled routes with OCsd $\geq 0.98$ but OCqd $<0.80$ as Shortest. The second condition eliminates the trips spatially close also to their quickest counterparts. Similarly, Quickest, Same, and Different groups are defined.

\section{ANALYSIS}

The trip group comparisons presented in this section are supported by Wilcoxon rank-sum and Wilcoxon signed-rank
TABLE II

Details for Data Selection Procedure

\begin{tabular}{clc}
\hline Name & Data selection & Trips \# \\
\hline Number of filtered simple trips 9/2012-11/2014 & 3308 \\
Number of trips considered for further analysis: & 2548 \\
\hline Shortest & $\begin{array}{l}\text { same as shortest counterparts but different from } \\
\text { quickest, i.e. OCsd } \geq 0.98 \text { and OCqd }<0.80 \\
\text { Quickest } \\
\text { the same as quickest counterpart but different } \\
\text { from shortest, i.e. OCqd } \geq 0.98 \text { and OCsd }<0.80\end{array}$ & 115 \\
Same & $\begin{array}{l}\text { same as shortest and quickest counterparts, i.e. } \\
\text { Oifferent }\end{array}$ & $\begin{array}{l}\text { OCqd } \geq 0.98 \text { and OCsd } \geq 0.98 \\
\text { differ from both shortest and quickest counter- } \\
\text { parts, i.e. OCsd }<0.80 \text { and OCqd }<0.80\end{array}$ \\
\hline
\end{tabular}

tests with 0.05 significance level.

\section{A. Analysis of driven trips}

In the dataset, trips are distributed similarly between the days of the week and months of the year. Distribution of driven trips by hour has peaks for Shortest trips close to rush hours. Different trips have bell-shape distribution with the maximum at day time. There are more Quickest trips in the late evening. Different trips spent more fuel per $\mathrm{km}$ than other groups of trips. Also, Different and Quickest trips of the analysed set are longer than Shortest (see Table IIII) This may indicate that it is easier to follow the shortest route when the number of alternatives is limited.

${ }^{5}$ Other test results, supporting claims in this article, can be found from: http://www.ee.oulu.fi/ gilkate/Support\%20material.pdf 


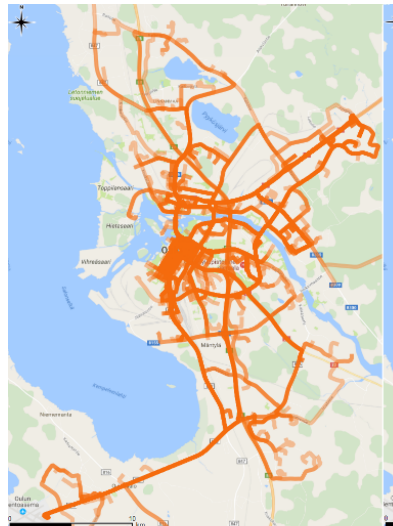

a) Different trips

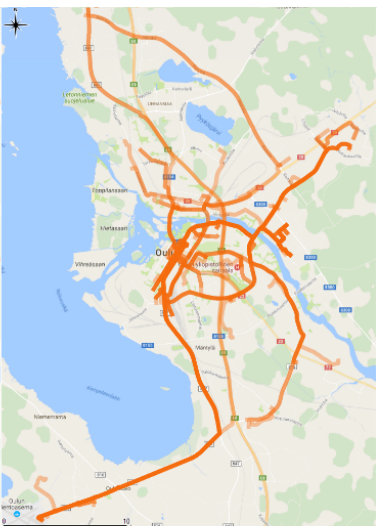

b) Shortest trips

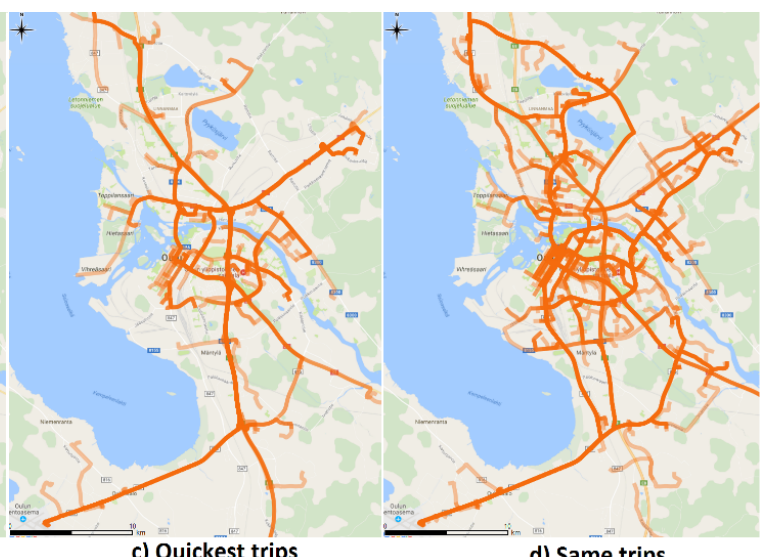

d) Same trips

Fig. 2. Routes comparison between trips (More intensive the colour, more frequently the certain road element was driven).

TABLE III

WILCOXON RANK SUM TEST FOR FUEL, DISTANCE, AND TIME FOR FOUR GROUPS OF TRIPS

\begin{tabular}{|c|c|c|c|c|c|c|}
\hline Factor & Different/Shortest & Different/Quickest & Different/Same & Shortest/Quickest & Shortest/Same & Quickest/Same \\
\hline & +35186 & +33182 & +227761 & +10604 & +43857 & -42631 \\
\hline fuel(1/km) & $(4.082770 \mathrm{e}-02)$ & $(1.779026 \mathrm{e}-11)$ & $(1.490806 \mathrm{e}-04)$ & $(4.667923 e-04)$ & $(4.026500 \mathrm{e}-01)$ & $(1.967967 \mathrm{e}-06)$ \\
\hline & +36804 & -66403 & +233123 & -5926 & +43826 & +79084 \\
\hline map_distance & $(1.510998 \mathrm{e}-01)$ & $(1.703253 e-09)$ & $(1.686799 \mathrm{e}-03)$ & (8.779117e-06) & $(4.074534 \mathrm{e}-01)$ & $(9.648422 \mathrm{e}-16)$ \\
\hline time $\min$ & +33007.5 & -54715.0 & +193622.0 & -6657.0 & +45228.0 & +74201.0 \\
\hline time_mm & (3.505033e-03) & $(6.662156 \mathrm{e}-02)$ & $(7.264169 \mathrm{e}-16)$ & $(9.514550 \mathrm{e}-04)$ & $(2.134063 \mathrm{e}-01)$ & $(1.885907 \mathrm{e}-10)$ \\
\hline total_fuel & $\begin{array}{c}+34134.5 \\
(\mathbf{1 . 3 8 2 5 1 5 e - 0 2})\end{array}$ & $\begin{array}{c}-61780.0 \\
(\mathbf{1 . 5 4 5 3 8 8 e - 0 5})\end{array}$ & $\begin{array}{c}+215575.5 \\
(\mathbf{1 . 1 4 2 1 8 5 e - 0 7})\end{array}$ & $\begin{array}{c}-5953.5 \\
(1.075402 \mathrm{e}-05\end{array}$ & $\begin{array}{c}+43767.5 \\
(4165570 \mathrm{e}-01)\end{array}$ & $\begin{array}{l}+76428.5 \\
+1027226 e-12)\end{array}$ \\
\hline
\end{tabular}

Cells contain W value (P-value). "+" means that alternative = "greater", "-" means alternative = "less". Differences at the 0.05 significance level are marked in bold.

Behavioural analysis. Different trips demonstrate significantly higher proportion of very low speeds and stops than other groups of trips, which negatively affects fuel consumption [10]. Shortest trips have higher proportion of speeds within $30-50 \mathrm{~km} / \mathrm{h}$, while Quickest trips follow more roads with speeds within $50-70 \mathrm{~km} / \mathrm{h}$, which positively affects fuel economy [10]. Different trips have also much less constant speed profile in comparison to other groups of trips. The most stable speed profile is registered for Quickest trips.

Route characteristics analysis. If we place the trips to the map, we will see that Shortest trips often follow the street roads, when Quickest trips prefer main roads (Fig 2). This potentially explains the variance in the speed factors observed between the trips in behavioural analysis. However, Different trips contain a quite diverse set road types. Same trips also show different patterns, however local roads are preferred as well. Spatial characteristics of the routes reveal that the majority of Shortest trips fall into roads with speed limit 40 and $50 \mathrm{~km} / \mathrm{h}$. That is, Shortest trips consist of less road but more street segments. Correspondingly, majority of Quickest trips are taken on motorway roads with higher speeds. Furthermore, it can be observed that different trips have the highest ratio of turns, crossings, and traffic lights. Accordingly, this shows in driving behaviour with difference in speed factors and consequently in the difference in the fuel consumption.

Weather analysis. A majority of the trips fall into good
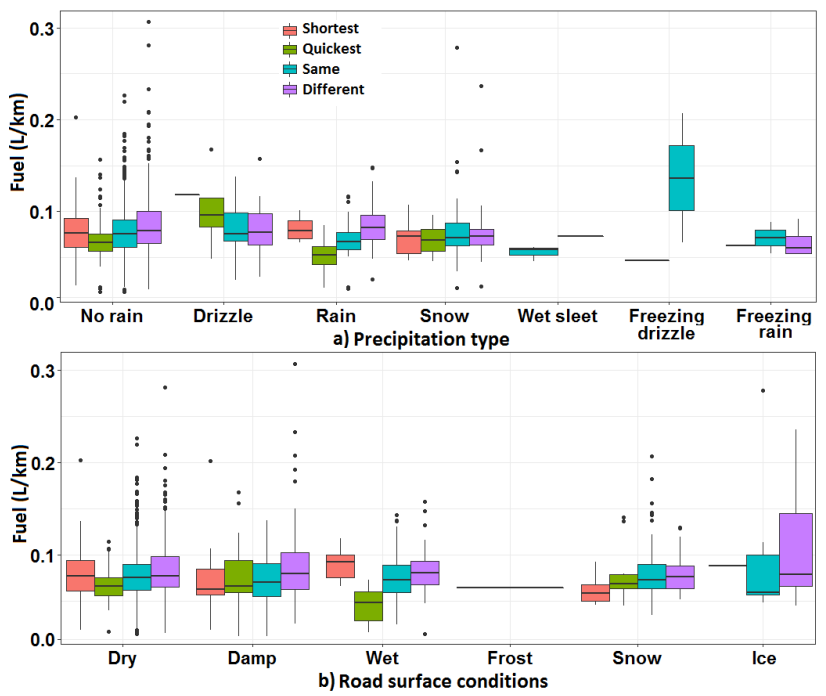

Fig. 3. Precipitation types and road surface conditions for Shortest, Quickest, Same and Different routes.

weather conditions, like dry road with no rain. For such conditions, Quickest trips present better fuel efficiency compared to other groups. Similar behaviour could be observed for wet road surface conditions, see Fig. 3

Traffic density analysis. From trips analysed, we removed trips with no traffic situation value, this resulted in 360 trips. 

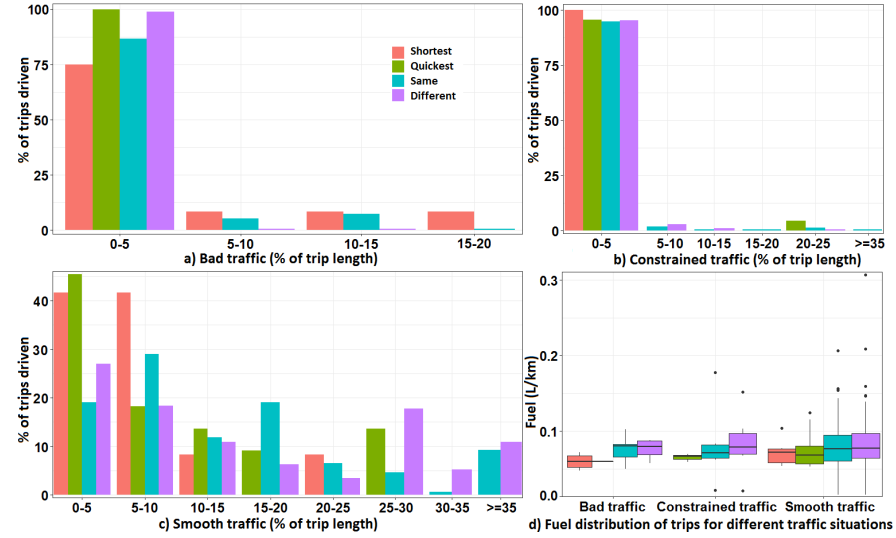

Fig. 4. Proportion of trips and fuel distribution for different traffic situations (360 trips).

With few occurrences, Shortest trips contained more cases with bad traffic than other groups of trips, see Fig. 4. This has logical connection to the types of the roads selected and speed profile observed.

\section{B. Analysis of driven trips and their shortest and quickest counterparts}

To find out potential fuel savings or losses associated with the selected route, we compare the actually driven Different trips in Table [I] with artificially created shortest and quickest versions. For clarity, we refer to these Different trips as Driven and to their shortest and quickest counterparts as Shortest_gen and Quickest_gen.

Driven trips analysis. Driven trips demonstrate more overlapping with longer Quickest_gen trips than with longer Shortest_gen trips, Fig. 5. This means that long Driven trips rather follow the quickest route than the shortest ones. In opposite, short-distance trips tend to overlap more with Shortest_gen. This is logical, as long trips often follow motorways, which are also preferred by Quickest_gen.

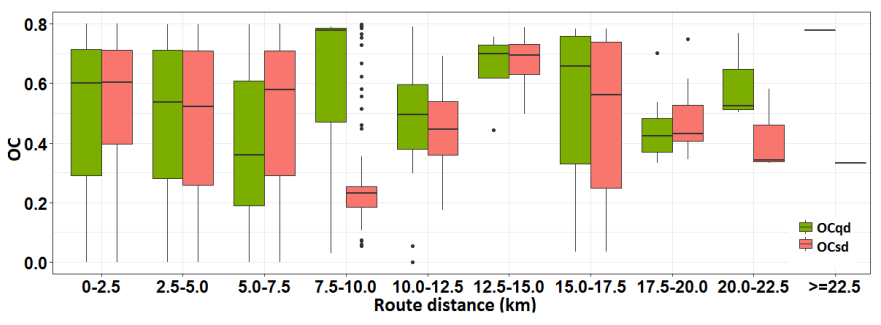

Fig. 5. Distribution of OC based on the distance of the travel.

Route characteristics analysis. Here, results resemble the ones observed for actually driven trips, like speed pattern. Shortest_gen trips follow more roads with low speed limits and less roads with higher speed limits in comparison to Driven and Quickest_gen. This can be explained with the types of the roads driven. Interestingly, the number of crossings in Driven trips is less than for the Shortset_gen ones, which is opposite in analysis of actually driven trips. Driven trips also have larger turn ratios in comparison to Shortest_gen and Quickest_gen.

Traffic density analysis. Due to lack of bad and constrained traffic cases, no interesting patterns were revealed here.

\section{Analysis from fuel-economy perspective}

To understand the effects of the route selection on fuel consumption, we compare the fuel spent by driven routes with estimated fuel consumption of their generated versions. Different machine learning and statistical techniques have been utilized for fuel prediction [8], [12]. In this study, we develop the generalized boosted regression model GBM (gbm library in $\mathrm{R}$ package) to predict the fuel $(1 / \mathrm{km})$ from the predictor variables describing trips' spatial and weather characteristics. We have also explored other machine learning models like kNN, C4.8, SVM and Neural Networks, but GBM proved to treat efficiently the complex relationships within our dataset.

For analysis, we use dataset of actually driven trips, Table II which resulted in 2447 trips after removing the outliers. This dataset was divided into 11 folds with caret $\mathrm{R}$ package. One fold is left for model validation (test set), the rest 10 folds (training set) were used to select the proper predictors and model training. We have used 10 -fold cross validation to select the feature set. Based on the predictor's importance, feature set was revised after each round and the most meaningful features were selected for the model. The task appeared to be difficult, as for artificially generated routes behavioural characteristics, having direct effect on fuel consumption, are not known, Fig. 6 Table IV lists the model predictors as well as their importance given by GBM.

Fig. 7 shows the effect of model predictors on fuel consumption. Rush hours, high proportion of crossings, traffic lights, turns ratio, the amount of $40 \mathrm{~km} / \mathrm{h}$ speed limit increase the fuel consumption. The effect of air temperature is harder to interpret; maybe the negative effects on fuel consumption could be explained by the use of air conditioning or opened windows.

We used the developed model to predict the possible fuel consumption on artificially created Shortest_gen and Quickest_gen routes. Quickest_gen trips have better fuel-efficiency per km than Shortest_gen, possibly because of the differences in types of the roads, their speed limits, number of crossings. To evaluate the overall fuel efficiency for the driven and generated routes, their length was multiplied to the predicted fuel per km. Fig. 8 shows the results for trips grouped by the
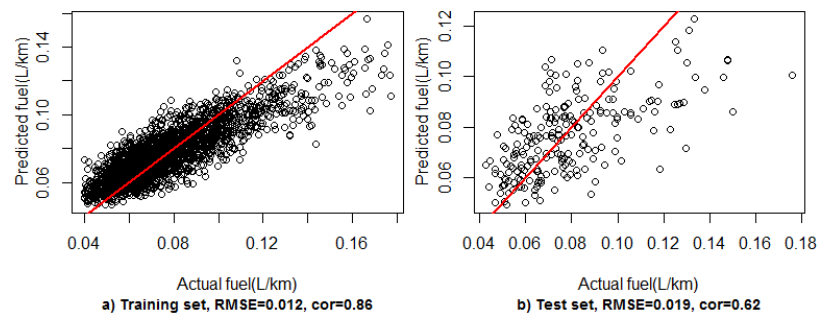

Fig. 6. Fuel prediction performance of selected model. 

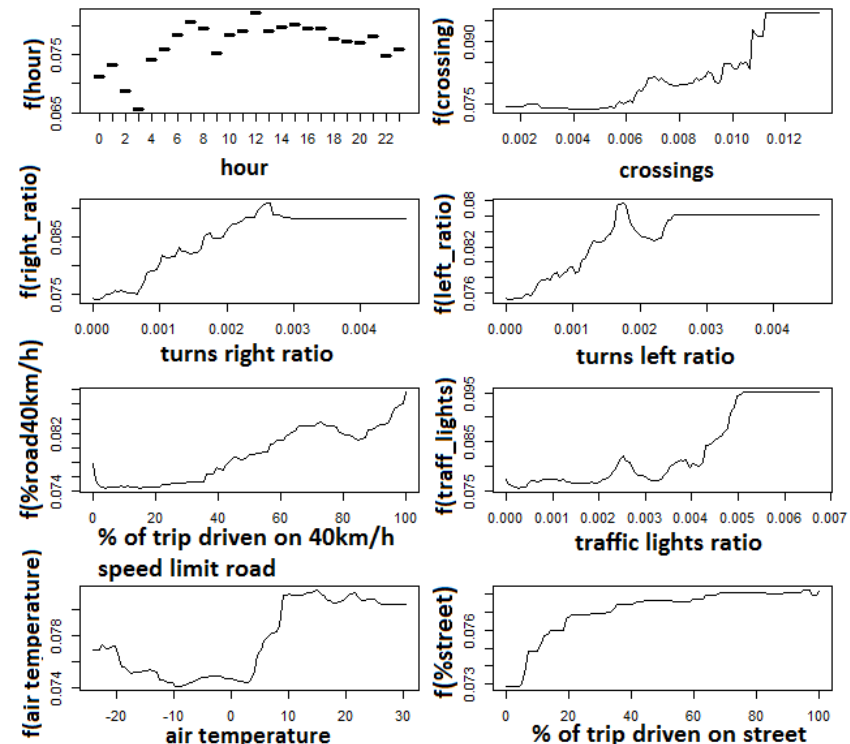

traffic lights ratio

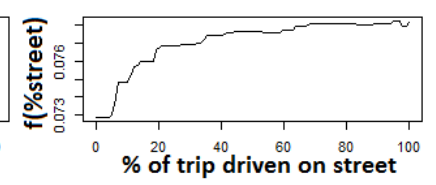

Fig. 7. Effects of the selected variables on the fuel consumption.

TABLE IV

PREDICTORS OF THE MODEL AND THEIR INFLUENCE

\begin{tabular}{ll}
\hline Predictor & Influence \\
\hline hour of day & 28.680350 \\
crossings & 11.327502 \\
$\%$ of the trip driven on the road with speed limit $40 \mathrm{~km} / \mathrm{h}$ & 6.546710 \\
ratio of turns right & 6.518235 \\
ratio of turns left & 6.148643 \\
traffic lights & 4.521123 \\
air temperature & 3.933696 \\
$\%$ of the trip driven on the road with speed limit $50 \mathrm{~km} / \mathrm{h}$ & 3.833127 \\
$\%$ of the trip driven on the road with speed limit $60 \mathrm{~km} / \mathrm{h}$ & 2.954860 \\
road surface temperature & 2.889482 \\
day of week & 2.856259 \\
$\%$ of trip driven on multiple carriageway, not motorway & 2.840442 \\
pedestrian crossings & 2.810359 \\
$\%$ of trip driven on feeder street/class I private road & 2.800542 \\
dew point & 2.517138 \\
$\%$ of trip driven on part of a single carriageway & 2.283501 \\
$\%$ of trip driven on local main street & 2.054013 \\
$\%$ of trip driven on slip road & 1.761632 \\
$\%$ of trip driven on road & 1.415402 \\
\% of trip driven on street & 1.306984 \\
\hline
\end{tabular}

length of the actually driven routes, to observe if there were any differences between short and longer trips.

As Fig. 8 shows, Driven routes demonstrated worse results in fuel consumption in comparison to Quickest_gen and majority cases for Shortest_gen. This can be explained by the fact that Driven trips are longer than Shortest_gen and some Quickest_gen. So, even though, the fuel spent per $\mathrm{km}$ could be higher for Shortest gen, the distance difference could result in fuel savings. Shortest_gen and Quickest_gen do not demonstrate statistically significant difference in fuel. However, for the longest trips $(\geq 17 \mathrm{~km})$, Quickest_gen spend less fuel than Shortest_gen regardless the difference in the route length. This can be explained by the road characteristics of Quickest_gen trips.

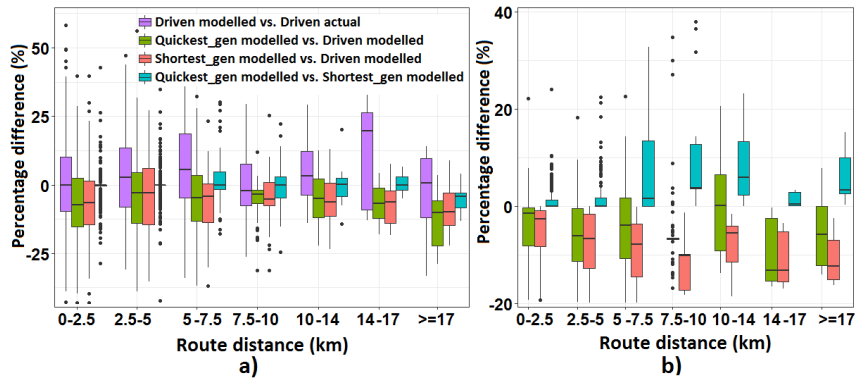

Fig. 8. Difference in fuel (a) and route distances (b) between driven and generated routes categorised by the length of the route.

Fuel consumption difference for the whole trip in percent is not very large, Fig. 8 That is, median savings for Shortest_gen are equal to $6.5 \%, 3.0 \%, 4.1 \%, 5.1 \%, 6.2 \%, 6.2 \%, 10 \%$ and median savings for Quickest_gen are equal to $7.2 \%, 3.0 \%$, $4.7 \%, 3.6 \%, 4.9 \%, 6.8 \%, 10.1 \%$ in comparison to modelled fuel for Driven trips for corresponding distance categories. In comparison, Ericsson et al. [11] reported about average potential savings of $8.2 \%$ from fuel-optimized route.

\section{DISCUSSION AND CONCLUSIONS}

In this article, we presented a complete empirical study for routes analysis. For this, we fused diverse kinds of data, including weather, traffic situation, driving behaviour, and geospatial information. Both routes and their generated quickest and shortest counterparts were analysed. Moreover, we developed a fuel consumption model and applied it to the route counterparts for possible fuel economy evaluation. Article presented thorough details on data processing, analysis, criteria selection, and model learning procedures. Moreover, article discusses challenges and limitations.

In our dataset, trips differing from both the shortest and quickest counterparts appeared to be less fuel efficient when compared to the trips following either the shortest or the quickest route. We also found differences in route characteristics and corresponding driving behaviour for these trip categories. Analysis of driven trips and their generated shortest and quickest counterparts revealed that longer trips rather follow the quickest counterpart, which is a logical observation, as long trips may follow motorways [30].

Developed in this article, fuel-consumption model demonstrated the route characteristics affecting the fuel consumption the most. Based on the model predictions, driven trips demonstrated worse fuel efficiency when compared to generated counterparts. When the quickest and shortest counterparts are compared, no significant difference is observed in our dataset. In comparison, Ericsson et al. [11] indicated that a fuelefficient route is often similar or close to the shortest one.

We found the following limitations and challenges. First, our analysis is based on the GPS locations and does not consider cognitive and physiological factors, as well as possible use of navigation tools, which may have an effect on route selection. This study does not focus on the factors affecting the route selection, but on route's effects on fuel consumption. We also 
treat the dataset as the whole, which is a common approach [11] allowing to abstract from individual features and to concentrate on the overall picture. However, our dataset is not large and it has been collected from few participants which may increase a single driver's impact on the results. Pruning of the dataset might bias the results as well, e.g. the similarity threshold has an effect on the selection of the trips and their classification.

For modelling alternative routes, we used artificially created shortest and quickest routes and this can generate some errors. A larger dataset would allow using actual trip data for alternative routes [18]. However, artificially created routes provide flexibility to set up own criteria for minimization. Also, the quality of available information affects greatly the prediction model and the results. Hence, the performance of the suggested model for fuel consumption prediction from route characteristics and weather could be affected by inaccuracy or incompleteness of information observed in digital map. Unfortunately, these kinds of issues are hard to eliminate, but they should be considered when interpreting the results. Of course, generalizing the results would require larger datasets from several different cities.

This study showed that taxi drivers follow the shortest route if the distance to travel is not long and the number of road choices is limited. Similarly, drivers follow the quickest routes more if the distance to travel is long. These decisions seem to be efficient from fuel economy point of view. Also, for longer trips, other factors like number of crossings are considered more important. We think that experience plays an important role, e.g. if there exists a hunch of congestion on some road drivers prefer to avoid it. The structure of the local region with few large roads somewhat limits the route alternatives. This also allows us to conclude that taxi drivers are well aware about the local region and best routes to select. Based on the study, we confirm earlier findings [19], [21], [24] that many factors affect the actual route choice of the drivers and these factors should be considered altogether. Hence, routing tools should incorporate different characteristics related both to the route and driving behaviour [14], [16].

Although there were limitations, we gained a lot of understanding about this topic and will tackle the challenges in our future work. For generalization of the results, a larger dataset would be needed. Also, understanding why certain route is preferred over the other is important; therefore we're planning to conduct a study where the drivers would give their opinions on routes selected. Additional sources of information about traffic density are required. For example, one possible solution is to utilize private or public transportation to serve as speed probes on the roads of the local region. Finally, we're interested in fusing other available data, e.g. information about traffic accidents.

\section{ACKNOWLEDGMENT}

This work has been funded by Tekes as part of the Data to Intelligence Program of DIGILE, EU Horizon 2020 project CUTLER: Coastal Urban development through the LEnses of Resiliency (770469), by Academy of Finland UrBOT: Enabling transient urban knowledge for future cities project (323630), and 6Genesis Flagship (318927).

\section{REFERENCES}

[1] G. Albert, T. Toledo, U. Ben-Zion, "The role of personality factors in repeated route choice behavior: behavioral economics perspective," European Transport $\backslash$ Trasporti Europei 48, pp. 47-59, 2011.

[2] M. Ben-Akiva, M.J. Bergman, A.J. Daly, R. Ramaswamy, "Modeling inter-urban route choice behaviour," In Proc. of the Ninth International Symposium on Transportation and Traffic Theory, VNU Science Press, Utrecht, Netherlands, pp. 299-330, 1984.

[3] E. Ben-Elia, R. Ishaq, Y. Shiftan, “ 'If only I had taken the other road...': regret, risk and reinforced learning in informed route-choice," Transportation 40, pp. 269-293, 2013.

[4] S. Brakatsoulas, D. Pfoser, R. Salas, C. Wenk, "On map-matching vehicle tracking data," In Proc. of the 31st international conference on Very large data bases (VLDB '05), pp. 853-864, 2005.

[5] K. Brundell-Freij, E. Ericsson, "Influence of street characteristics, driver category and car performance on urban driving patterns," Transportation Research Part D: Transport and Environment, 10 (3), pp. 213-229, 2005.

[6] P.S. Castro, D. Zhang, C. Chen, S. Li, G. Pan, "From taxi GPS traces to social and community dynamics: A survey," ACM Comput. Surv., 46(2), Article 17, 2013

[7] C. Chen, D. Zhang, Z.-H. Zhou, N. Li, T. Atmaca, S. Li, "B-Planner: Night bus route planning using large-scale taxi GPS traces," In Proc. of the IEEE International Conference on Pervasive Computing and Communications (PerCom'13), pp. 225-233, 2013.

[8] E. Demir, T. Bektaş, G. Laporte, "A review of recent research on green road freight transportation," European Journal of Operational Research, 237 (3), pp. 775-793, 2014.

[9] Z. Duan, Y. Wei, "Revealing Taxi Driver Route Choice Characteristics Based on GPS Data," CICTP 2014, pp. 565-573, 2014.

[10] Ericsson, E., "Independent driving pattern factors and their influence on fuel-use and exhaust emission factors," Transportation Research Part D: Transport and Environment, 6(5), pp. 325-345, 2001.

[11] E. Ericsson, H. Larsson, K. Brundell-Freij, "Optimizing route choice for lowest fuel consumption - potential effects of a new driver support tool," Transportation Research Part C: Emerging Technologies, 14(6), pp. 369-383, 2006.

[12] W. F. Faris, H.A. Rakha, R.I. Kafafy, M. Idres, S. Elmoselhy, "Vehicle fuel consumption and emission modelling: an in-depth literature review," International Journal of Vehicle Systems Modelling and Testing, 6 (3-4), pp. 318-395, 2011.

[13] E. Gilman, A. Keskinarkaus, S. Tamminen, S. Pirttikangas, J. Röning, J. Riekki, "Personalized assistance for fuel-efficient driving," Journal of Transportation Research Part C: Emerging Technologies, 58(D), pp. 681-705, 2015.

[14] E. Gilman, G.V. Georgiev, P. Tikka, S. Pirttikangas, J. Riekki, "How to support fuel-efficient driving?," IET Intelligent Transport Systems, 12 (7), pp. 631-641, 2018.

[15] T. Guan, C.W. Frey, "EXPERT: A Driver Assistance System for Fuel Efficient Driving," In Proc. of the 3rd International Conference on Machine Control \& Guidance, pp. 27-29, 2012.

[16] S.L. Jamson, D.L. Hibberd, A.H. Jamson, "Drivers' ability to learn eco-driving skills; effects on fuel efficient and safe driving behaviour," Transportation Research Part C: Emerging Technologies, 58(D), pp. 657668, 2015.

[17] X. Jiang, Y. Ji, M. Du, W. Deng, "A study of driver's route choice behavior based on evolutionary game theory," Computational Intelligence and Neuroscience, Article ID 124716, 10 pages, 2014.

[18] M. Lu, C. Lai, T. Ye, J. Liang, X. Yuan, "Visual analysis of route choice behaviour based on GPS trajectories," In Proc. of IEEE Conference on Visual Analytics Science and Technology (VAST), pp. 203-204, 2015.

[19] E.J. Manley, J.D. Addison, T. Cheng, "Shortest path or anchor-based route choice: a large-scale empirical analysis of minicab routing in London," Journal of Transport Geography 43, pp. 123-139, 2015.

[20] E.J. Manley, S.W. Orr, T. Cheng, "A heuristic model of bounded route choice in urban areas," Transportation Research Part C: Emerging Technologies 56, pp. 195-209, 2015.

[21] D. Papinski, D.M. Scott, "A GIS-based toolkit for route choice analysis," Journal of Transport Geography, 19(3), pp. 434-442, 2011. 
[22] D. Papinski, D.M. Scott, "Route choice efficiency: an investigation of home-to-work trips using GPS data," Environment and Planning A, 45(2), pp. 263-275, 2013.

[23] M.S. Ramming, "Network knowledge and route choice," $\mathrm{PhD}$ thesis. MIT, 2002.

[24] F. Saremi, O. Fatemieh, H. Ahmadi, H. Wang, T. Abdelzaher, R. Ganti, H. Liu, S. Hu, S. Li, L.Su, "Experiences with GreenGPS - Fuel-Efficient Navigation using Participatory Sensing," IEEE Transactions on Mobile Computing, 15(3), pp. 672-689, 2016.

[25] P.Senk, "Route choice under the microscope," Transport. Res. Rec.: J. Transport. Res. Board, 2156 (1), pp. 56-63, 2010.

[26] M. Sivak, B. Schoettle, "Eco-driving: strategic, tactical, and operational decisions of the driver that influence vehicle fuel economy," Transport Policy, pp. 96-99, 2012.

[27] C. Vagg, C.J. Brace, D. Hari, S. Akehurst, J. Poxon, L. Ash, "Development and field trial of a driver assistance system to encourage eco-driving in light commercial vehicle fleets," IEEE Transactions on Intelligent Transportation Systems, 14 (2), pp. 796-805, 2013.

[28] E.J. Yao, L. Pan, Y. Yang, Y.S. Zhang, "Taxi Driver's Route Choice Behavior Analysis Based on Floating Car Data," Applied Mechanics and Materials, Vols 361-363, pp. 2036-2039, 2013.

[29] W. Zhang, S. Li, G. Pan, "Mining the semantics of origin-destination flows using taxi traces," In Proc. of the Workshop of Ubiquitous Computing, pp. 943-949, 2012.

[30] S. Zhu, D. Levinson, "Do people use the shortest path? An empirical test of Wardrop's first principle," PLoS ONE 10(8): e0134322, 2015.

(C) 2021 IEEE. Personal use of this material is permitted. Permission from IEEE must be obtained for all other uses, in any current or future media, including reprinting/republishing this material for advertising or promotional purposes, creating new collective works, for resale or redistribution to servers or lists, or reuse of any copyrighted component of this work in other works 